\title{
Edith Cowan University
}

\author{
Ffion Murphy
}

\section{Writing therapy: paradox, peril and promise}

\begin{abstract}
$\underline{\text { Abstract }}$
Belief in the remedial potential of the writing process has intensified in the past three decades, with scientific studies indicating health and wellbeing benefits; poets, novelists and memoirists proclaiming therapeutic effects; and, innovative and broad-ranging use of creative writing in counselling and health care. This paper proposes that tertiary writing education can benefit from the explicit study of writing therapy as a complex, evolving and contested set of theories and practices. It outlines and contextualises my own approach, discusses some relevant literature, and proposes future interdisciplinary mixed-methods research, for the time is ripe in Australia for writing and health teachers and researchers to work together to investigate writing's risks, paradoxes and recuperative possibilities.
\end{abstract}

\section{Biographical note:}

Ffion Murphy is a Senior Lecturer in the School of Arts and Humanities at Edith Cowan University. Her publications include journal articles, book chapters and edited books on literature and writing and a novel, Devotion (2006). She is currently investigating aspects of recuperative writing relating to the First World War.

\section{Keywords:}

Creative writing - Writing therapy - Teaching - Literary therapeutics - Mental health 


\section{Introduction}

My investigations of writing therapy began in the late 1990s as part of the doctoral research for a thesis comprising a novel and critical essay. In the novel, Devotion (2006), the protagonist Veronica becomes partially paralysed and then mute following the difficult birth of her second child. Because her doctors can find no organic causes, Veronica becomes an object of speculation, with a history to be discerned and cured. Her analyst Andrew Moore, frustrated by her silence, prescribes writing as therapy and a computer. In response to opposition from other medical staff, who argue 'leaving patients to their own imaginings' could be dangerous, for they need 'guidance in reconstructing the past' (24), Moore asserts that 'all over the world' there is mounting evidence that writing is 'an effective form of therapy'. He insists that it is 'not about catharsis or spilling your guts', but about 'grappling with images, fragments and symbols, understanding them, overcoming resistances, reconciling, breaking unconscious cycles of repetition and moving on'. The process, he adds, requires the 'construction of stories, of coherent narratives', so that Veronica would need to 'create or recreate the past in the present if it was to have a therapeutic result' (Murphy 2006: 22-3). Not fully disclosing his intentions, Moore accesses Veronica's words illicitly and assumes he is witnessing her recovery.

In the novel, writing becomes essential for Veronica, even as she perceives its perils: 'this screen breeds demons. But now it's essential, like touch or breathing' (62). Over time, confounding Moore's prognosis, she writes herself further into illness, not out of it, for her imaginings and justifications go unchallenged. Moore fails to understand Veronica's delusions or intentions, fatally misreading her. Finally, he must recalibrate: he had thought that 'writing was enough, that it'd somehow stitch the wounds. That it'd make her a mirror to see things clearly. But it was a mirror of enigmas' (292).

Devotion exploits the conventional metaphor of the wound as a source of stories, as well as contemporary belief in the efficacy of telling our own stories. The latter view, which the novel seeks to complicate, grew during the twentieth century with psychoanalysis - in particular with Freudian notions of the 'talking cure' and the therapeutic value of constructing convincing explanatory narratives. The patient's writing of her own story creates an expectation of cure consistent with a liberatory feminist and poststructuralist politics of 'writing the self'. Furthermore typically, in 'wounded storytelling', metaphors of wreckage link to those of repair, enabling transformative and redemptive narratives (Frank 1995). Brooks reminds us, however, that while stories are a way of seeking knowledge and establishing truth, this will be incomplete, provisional and constructed, 'a necessary hermeneutic fiction' (1992: 304). Foster proposes that 'what narrative teaches is ignorance, every reader's lack of knowledge; it is a lesson that ensures the struggle to understand will find no conclusion' (1997: 7). Neither writing nor reading guarantee clarity and understanding, nor truth, empathy or virtue for that matter. Many factors come into play, including desire, which may be inconsistent, conflicted, feared or repressed. The writer might struggle consciously or otherwise - with competing or co-existing imperatives. An apparent revelation or confession can mask evasion. Some writing might prove more blade than balm, more poison than potion. There are different ways of remembering and narrative can be a way of recounting the past but also of repeating it. Storytelling can become a 
strategy of denial and rationalisation, as well as positive change and regeneration. Amid considerable enthusiasm for writing as an efficient, cost-effective intervention, Devotion offers a cautionary tale.

In 2008, after revisiting and expanding my doctoral research, I offered at my university a new one-semester unit, Writing Therapy, to explore with students psychotherapeutic, literary and scientific discourse on the therapeutic potential of writing and engage them in various writing experiments to consider their possible effects. ${ }^{1}$ The unit continues to be reimagined and reconfigured; it remains a work-in-progress that uses practice-based research, among other methods, to address questions such as how did writing therapy discourse come about, what are its meanings, what does it disrupt, whom does it serve and what personal and social changes might writing facilitate. The approach is 'research-informed teaching' which, in bringing research and teaching 'closer together', supports students in 'learning about others' research'; 'learning to do research'; and 'learning about their discipline in research or inquiry mode' (Embedding Research 2013). Writing Therapy contributes to debates concerning the political, cultural and educational contexts in which student writing takes place. Responding to Paulo Freire's critical pedagogy, it both insists 'education is a struggle to improve human existence' (qtd. in Benesch 2008: 47) and promotes the importance of 'dialogue about emergent themes that leads to greater understanding of their contradictions and their historical context, and formulation of ways to respond to them' (49).

This article proposes that university writing programs integrate and interrogate writing therapy as a complex, evolving, multifaceted and multi-disciplinary set of theories, approaches and practices. I offer a literature review sufficient to indicate some of writing therapy's contradictions and challenges. Following discussion of my Writing Therapy unit as a possible model, I recommend future interdisciplinary mixed-methods research be done to evaluate student experiences of writing therapy in the educational context and whether writing therapy could be used explicitly, strategically and adjunctively to improve health and wellbeing among university students. The term 'writing therapy', as used herein, embraces acts of literary and expressive writing that may or may not have been prescribed by a health professional and which are undertaken to achieve, or inadvertently achieve, a beneficial physiological, cognitive, emotional, social or psychological change in the writer. This may be subjectively or scientifically ascertained and may co-exist with other motivations or effects, including literary aims such as entertaining, informing and giving aesthetic pleasure to readers. I capitalise the term only when referring to the teaching unit.

Common to the mediums through which I have explored this topic (novel, essays, teaching) is the concept of writing's paradox, peril and promise. Initially, my intrigue was largely with the former two, but after more than a decade of inquiry I am finding that what increasingly interests me is its promise.

\section{Writing as therapy: a brief review}

Social psychologists Sexton and Pennebaker claim that since the 1980s 'the value of expressive writing has made the transition from anecdotal folk wisdom to a large and growing body of scientific research' (2009: 264). Pennebaker's studies have played a 
key part in this transition. He and Beall inaugurated random controlled trials (RCTs) of expressive writing in 1986, focussing on disclosure and posing the question 'What aspects of confiding a traumatic event reduce physiological levels and disease rates?' (Pennebaker and Beall 1986: 274). Their writing intervention required college students to write for 15 minutes on four consecutive days. Sexton and Pennebaker claim that, since then, over 200 laboratory studies by numerous researchers suggest mental and physical health benefits can be found, for example, across 'college students, maximumsecurity psychiatric inmates, unemployed engineers, Holocaust survivors, and also patient cohorts who suffer from ailments such as chronic pain, arthritis, asthma, breast cancer, and post-traumatic stress disorder'. Results come from labs across the world, including 'the United States, Mexico, the Netherlands, Spain, Italy, and New Zealand'. Writers also gain benefits from writing about their 'best possible selves' or 'positive experiences' and about real as well as imagined trauma, so it is 'not necessary to take on a literal or journal style of writing to find gains' (2009: 267-68). Croom also finds empirical and theoretical evidence that writing poetry or narrative increases or improves 'positive emotions, engagement or flow experiences, interpersonal relationships, meaning or purpose in life, and personal accomplishments', thus scoring well against positive psychology wellbeing measures proposed by Martin Seligman (2015: 36-37).

Meta-analyses of quantitative studies have been important in confirming positive effects, as well as variability of effect sizes and areas for further research. Frattaroli's analysis of 146 studies of expressive writing (2006) for example found, as Travagin, Margola and Revenson point out, that particular groups experienced greater benefits, with 'larger effects among those who had higher stress, poor physical health, and lower optimism before writing', so that expressive writing could be a useful intervention to foster 'emotional regulation and wellbeing in vulnerable populations, especially in light of its cost-effectiveness'. Travagin, Margola and Revenson conducted their own metaanalysis to assess the effects of Pennebaker's writing intervention among adolescents, and concluded that expressive writing 'tends to produce small yet significant improvements' in wellbeing. They emphasise the importance of modifying the traditional protocol for different cohorts 'to enhance its efficacy and reduce potential detrimental effects' (2015: 44).

For Lu and Stanton meta-analyses reveal 'significant heterogeneity on many outcomes', so that, as we might expect, effects vary as a 'function of experimental parameters, including the specific psychological processes targeted in the experimental task, outcomes assessed and individual differences'. For this reason, they say it is essential to understand 'the conditions under which expressive writing works and how to maximise its benefits' (2010: 670). Similarly, Range and Jenkins point out that some studies report 'no physical or psychological improvement' and 'a few projects found writing harmful', adding 'the impressive benefits from writing usually but do not always occur, so an important goal is to mediators and moderators of what works for whom, and why' (2010: 150). While it is concerning that some studies find writing may have short term adverse effects, the examples provided by Range and Jenkins seem unlikely to impact significantly on university cohorts. For example, they explain that

Among 40 inpatient men undergoing transurethral prostate resection, those at low risk benefited, but those at high risk declined slightly ... Among 14 Israeli adults ( 8 women, 
6 men) with posttraumatic stress disorder (PTSD), trauma writers had more health clinic visits ... Among 23 lower limb amputees, stronger emotional disclosure correlated with reduced prosthesis satisfaction (2010: 150).

More relevant, it seems, are the potential negative effects of expressive writing on mood and cognition. Forgeard, Kaufman and Kaufman conclude that where writing encourages 'self-reflective rumination', it might make individuals 'feel worse' for a while (2013: 324); however, they point to the paradox that writing can also 'provide an avenue for coming out of the vicious circle of rumination' (325). In a study by Gortner, Rude and Pennebaker, for example, participants wrote for twenty minutes on three consecutive days about their 'deepest thoughts and feelings on current and past emotional upheavals' (2006: 294-95). Expressive writing was found to lower rumination and depressive symptoms, which were measured prior to the trial and at five weeks and six months afterwards.

Various factors appear responsible for writing's positive effects, including the opportunity for disclosure, disinhibition, catharsis, image-making, emotional expression, cognitive restructuring, changed perspectives, attention, habituation, selfregulation, and creation of structured, explanatory narratives (Bucci 1995; Baikie and Wilhelm 2005; Pennebaker and Chung 2007; Sexton and Pennebaker 2009). According to Pennebaker and Chung, writing a coherent, explanatory story involves translating inchoate emotions into words in such a way that events achieve 'knowledge status' (2007: 277): 'This analog-to-digital process demands a different representation of the events in the brain, in memory and in the ways people think on a daily basis'. But the authors acknowledge that 'the overall effect size of writing is modest' (279) and that researchers have not yet been able to 'precisely define what is meant by coherent, understandable, or meaningful when it comes to writing about emotional upheavals' (276). Furthermore, as they note, therapeutic outcomes can sound 'almost magical' if they are attributed only to the writing sessions in the experimental paradigm - usually 15 or 20 minute sessions on between three and five consecutive days. The apparent ease of gaining benefits might partly explain the popular take-up of writing as therapy (and the suspicion this evokes) but it underestimates the 'cascade of effects' initiated by the writing process; for example, Pennebaker and Sexton explain it may trigger dreams and frequent thoughts about the topic between sessions and beyond the trial; increase working memory where it helps participants spend 'less cognitive effort' on troubling events; and stimulate conversations on the topic, bringing about valuable personal interactions, all of which might bring about positive 'changes in people's social lives' (279).

Keating and Rains (2014), like many other researchers, assert that more research needs to be done to extend understanding of precisely why, when, how much, in what ways and for whom writing is beneficial. Writing shares many of the benefits claimed for other arts therapies, according to King, Baker and Neilsen, including 'behavioural activation', 'self-efficacy/mastery', 'overcoming experiential avoidance', 'strengthening of personal identity' and 'social connectedness' (2016: 2-3), but its linguistic base sets it apart, so that, for example, it may be unsuitable for young children; where there are 'cognitive limitations'; where a person is inhibited or fearful; or where it would be too painful to tell a particular story (6). In a university context, where 
linguistic competence is a prerequisite, mental disabilities and trauma might nevertheless restrict a student's ability to participate in some types of writing. Lack of motivation or interest in writing might also make it unappealing for some students.

When expounding the use of creative arts in counselling and mental health, King, Baker and Neilsen acknowledge that aligning creative activity with therapy 'might sound counterintuitive given popular associations of creativity and madness'. However, they are not convinced creative people are 'more emotionally unstable than the rest of the population'; instead, creative activity may be 'a stabilizing force for people who otherwise would be much less able to manage in life' (2016: 1). In 'Creative myth conceptions', Schlesinger also attempts to debunk the association, proposing that the 'mad creative' or 'mad genius' is a 'cherished cultural icon' and 'romantic and compelling concept' that has 'unfortunate implications' for 'perceptions of creativity' (2009: 62). She demonstrates that 'scientific evidence' connecting creativity and pathology cannot be relied upon as it mostly references deeply flawed studies by frequently-cited creativity researchers Andreasen, Ludwig and Jamison. She finds no clear, convincing evidence that artists suffer more psychological problems than any other vocational group. Further tackling popular misconceptions, Kaufman and Paul assert that creativity research has now established that 'mental illness is neither necessary nor sufficient for creativity' and that 'suffering' is not a requirement for 'people who engage in everyday forms of creativity'; indeed, those 'scoring high in everyday creativity also tend to report feeling a greater sense of well-being and personal growth compared to their classmates who engage less in everyday creative endeavours'. While mental illness may be present in some who achieve eminence (and no doubt in some who do not), it is more likely to hinder than contribute to 'productivity and innovation' (2014: 1).

The narrative connecting creativity and psychopathology is resilient, despite its critics and, given persistent prejudice, it can play out at a cost to some students. Although kudos attaches to the label 'creative' (and even to 'mad' if combined with 'genius'), it is undone by amateur status; thus, students can be typecast and stigmatised simply for their choice to study creative writing. Bishop observes that 'author myths' can suggest to both teachers and students that those drawn to writing classes are 'wild' or 'liable to depression and suicide' or 'feel more' than others, making them 'at risk' (1993: 506). In a stark example, following the massacre of 32 students at Virginia Tech in 2007, where the perpetrator was an English major and creative writing student, there ensued much discussion among educators about the mental health of writing students in general, with higher than average rates of dysfunction or aberration assumed (Murphy 2008). Australian teacher and author Kerryn Goldsworthy claimed, 'Classes in creative writing do, in fact, bring nutters out of the woodwork' (Arts and letters 2007), while in the UK, Blake Morrison whimsically suggested, 'if creative writing programmes excluded students with personality disorders, they would all have to close down' (2007). Choosing to study a unit called 'writing therapy' might amplify this situation, raising the question of whether some students enrolling in the unit are doing so in the hope of psychological benefits. Should this be the case, the choice signals agency and initiative in relation to their health and wellbeing, but it is nevertheless important to establish the unit's limitations in this respect, a point I return to below. 


\section{Mental health on campus}

Universities are sites of great social, cultural, physical and neuro diversity. Mental illness and anxiety are common. Recent studies of Australian university students suggest that at least one in four may at any time be experiencing some form of mental health challenge. Furthermore, students who are young, female, in a sexual minority or enrolled in arts or social science courses are at higher risk of anxiety and depression than the rest of the population and other university students (Stallman 2010; Norton and Brett 2011; Larcombe et al. 2014; Wynaden, Wichmann and Murray 2013). Improving student health has become a major concern for educators and university administrators, as is suggested, for example, by the forthcoming Inaugural Australasian Mental Health and Higher Education Conference to be held in Townsville, Queensland in 2017.

Stallman highlights the need for early interventions 'to prevent the development of severe mental illness in university students' (2010: 249). But seeking to identify and intervene with populations 'at risk' may run its own risk. In Therapy Culture, Furedi claims the concept of being 'at risk' emerged in the 1980s as part of 'crisis thinking', and to be considered at risk is to be assigned a 'passive and dependent role' (2004: 130). He contends that therapeutic discourse does not liberate human potential, but instead 'illustrates the interplay between risk and powerlessness' (8). Similarly, Ecclestone and Hayes criticise what they see as 'the dangerous rise of therapeutic education' (2009: viii), which 'privileges the emotional' and 'denies the intellectual,' leading to a 'diminished human subject' (87). They identify a cultural shift that sees learners as vulnerable (87), so that the therapeutic university's 'ethical purpose' becomes supporting students and making them feel 'safe and secure'. Claiming this has become a 'major focus of university work', they argue for a return to the privileging of reason and subject knowledge (96) but, I posit, the two are not mutually exclusive.

\section{Writing therapy}

For various reasons, a writing unit cannot offer a health intervention, not least because students must be assessed for academic credit. It can, however, expose students to competing ideas and prejudices concerning creativity and pathology, and also to 'literary means to therapeutic ends' 2 and therapeutic means to literary ends, including claims of their incompatibility or inextricability.

Therapeutic motivation or effect, which might suggest the emotional, pathological or disorderly, may be discouraged by university composition and creative writing programs for fear of undermining creative and critical thinking and compromising the quality and status of literary work, while also possibly risking the health and wellbeing of students and educators not equipped to assist others or themselves should the writing process amplify grief, pain, anxiety or mental disorders. The latter concern is not unfounded given that emotional activation, as well as cognitive work, is 'necessary for therapeutic change' (Pennebaker and Chung 2007: 272). As Hecq argues, reading and writing are 'psychological affairs in which intellect and emotion, as well as conscious and unconscious processes interplay' (2015: 34). Importantly, reflection and drafting generally enhance image development and cognitive processing, which can improve the likelihood of a therapeutic effect. These processes also potentially improve 
students' writing, so that despite differences in purpose and focus, therapeutic, literary and pedagogical objectives potentially cohere.

The latest iteration of the biennial Writing Therapy unit in 2015 marked a substantial shift and more appropriate direction. This view is supported by students' verbal and written feedback and generic end-of-semester unit evaluations. ${ }^{3}$ As a reflective practitioner, I came to realise that my earlier approach was conservative and inflected by precisely the kinds of prejudice and defensiveness I had imagined the unit was interrogating and overcoming. I was anxious to ensure that the unit would be deemed academically rigorous to anyone who happened to question it, given its foray into the murky world of therapeutics. In other words, it had to present as anything but a haven for students misguidedly looking to writing as a mental health resource. Hence, departing from other writing units, students were initially expected to produce substantial annotated bibliographies, précis quantitative and qualitative research, and write a lengthy academic essay. A short personal narrative, accompanied by an explanatory essay, was the primary creative writing task. Writing exercises were a relatively minor part of workshops dominated by historical and theoretical material. This approach, intended to legitimate the unit's place in the academy, in fact, overlooked the importance of arts-based or practice-based research.

The Writing Therapy unit was founded on curiosity and ambivalence and, despite significant revisions, my pedagogical approach remains interrogative: we continually question the concept and practice. Quantitative studies can seem alien and reductive in design and somewhat optimistic in their conclusions. We might also remain suspicious of 'technologies of the self' (Foucault 1988) and a personal salve that could subdue or replace political activism. On the other hand, theoretical insights and empirical evidence continue to emerge from the sciences and humanities about the progressive social and cultural value of memoir or testimonial works their writers deem therapeutic in motive or effect.

For students, the practice-based method involves testing, evaluating and communicating their experiences of different forms of creative and expressive writing, while also reflectively negotiating issues of interpretation and bias due to the pedagogical context and their increasing knowledge of the field. Students review literature, write experimentally, keep a journal, and communicate their reflections and evaluations in group discussions and exegetical and reflective essays. They explore influential quantitative research into expressive writing since the 1980s, beginning with Pennebaker's work, and are progressively introduced to relevant discourses of creativity, literature, illness, psychoanalysis, bibliotherapy, memory, trauma and testimonial life-writing and related fields such as narrative therapy, narrative medicine and medical humanities. ${ }^{4}$ The underpinning approach concerns voice and agency - who tells, who listens, whose stories prevail, how are plots and metaphors enabling or disabling, and how do language and genre produce, shape and limit identities, bodies and emotions. Students are encouraged to consider the validity of writing as a source of knowledge and to articulate its experiential nature (Hecq 2015). They consider the ways stories are 'always already ideological', shot through with 'shaping myths' and metaphors (Clark 2008: 4). Students review criticisms of 'confessional', 'misery' and 'sick' literature, as well as 'therapy culture', and also progressive, liberatory uses of 
autoethnography and 'wounded storytelling' (Frank 1995). They consider the challenges of 'bearing witness', ethical issues in personal writing, and community uses of therapeutic writing, such as creative writing programs in prisons, aged-care facilities and hospital wards. Readings include samples of quantitative research, case studies, cultural commentary, practical and theoretical texts, poetry and short narratives, guidebooks and descriptions of community applications. ${ }^{5}$

Each week students engage in writing experiments, some of which have playful elements $^{6}$, such as adapting origin myths or freely associating in response to visuals; they trial intuitive, cathartic, descriptive and reflective journaling (Rainer 2004); sixword memoirs; fictional autobiography (Hunt 2000); poetry springboards (triggered by published poems); illness stories and letter therapy. They also engage in deconstruction exercises drawing on 'narrative therapy' principles and questions - that is, selecting and externalising 'the problem', deconstructing it, drafting a 'dominant' self-story and an alternative story, and then integrating and developing these 'thin' stories to enrich and thicken the plot, with a view to producing more nuanced narratives of the historicised self in its particular social context (Morgan 2000). In their reflective essays, students choose a few writing experiments to focus on and many choose 'Letter therapy', claiming it has had the greatest emotional impact on them. The exercise involves 'three consecutive writes, using the same technique, each building on the one before it' (Adams 2006: 142). Letter therapy offers an opportunity to present a complete point of view and then follow up with different perspectives. ${ }^{7}$ For their major assessment, students produce a creative piece and brief essay. As a useful exemplar, they consult Writing Routes (Bolton, Field and Thompson 2011), which collects seventy short creative works by contributors with diverse creative writing, psychotherapy, teaching and counselling backgrounds. Each of the pieces is accompanied by a piece explaining 'how they came to write' it, 'what it said back to them', what problems arose, and 'in what way it was helpful to them' if indeed it was (11). The assignment refers them to Writing as a way of healing: How telling stories transforms our lives by DeSalvo (1999) and to Poetry and Story Therapy by Chavis (2011), so that students aim for accuracy, concrete images and telling details and also consider their work from a therapist's perspective: Chavis indicates there is great scope for diversity in terms of genre, subject matter and approach, but that 'if a story has mostly tragic elements' it will also contain 'at least a suggestion of positive possibilities' (100). Students may convey traumatic or shameful experience if that is what they want to do, and they might do this directly or by telling it slant, but such content is not privileged over other topics.

Some teachers convincingly attest to the social and affective benefits of examining trauma texts, using pedagogies variously described as critical, engaged, progressive, feminist and psychoanalytic. For Felman, 'the process of the testimony - that of bearing witness to a crisis or a trauma - [can] be made use of in the classroom situation' (1995: 13) to produce a traumatic encounter that cuts through to learning. She seeks Elias Canetti's visceral response to reading Kafka's correspondence, which he says 'penetrated' him 'like an actual knife' (14). For Friedman, reading trauma texts is a strategy to heighten engagement and foster 'mindful, ethical behaviour, empathy and wellbeing' (2007: 17) leading to 'self-transformation and social change' (iii). 
Engaging in self-disclosing writing about trauma and shame may also be a means to transformative learning and social benefits. Berman, a psychoanalytic literary critic, believes students' writing skills are enhanced by exploration of such 'risky' material, for it secures 'their full engagement in a compelling rhetorical situation' and supports 'education of the emotions' (2001: 9). ${ }^{8}$ Dutro similarly advocates the 'exposing of wounds' by teachers and students to 'foster the kinds of relationships and stances necessary to challenge entrenched inequities and privileged assumptions about Others' lives' (2011: 194).

Although the Writing Therapy unit deals at times with distressing material as part of a reading or when it emerges spontaneously from students, such as might occur in any writing class, it does not subscribe to 'crisis' education, which describes situations where encountering trauma texts is intended to create empathic awareness. I think such an approach could be effective but do not have the skills or inclination to develop it. Spear adopts instead a 'wounded healer pedagogy' that focuses on healing as an ongoing process for authors and readers, rather than on trauma, which seems a preferable method in terms of moderating risk. Citing Julie Rak, Spear asserts that it is not necessary to 'risk wounding students in order to teach them something about wounding' (2014: 56).

Critics of personal writing in the academy worry that a focus on wounding and personal experience encourages anti-intellectual, solipsistic work that might also invite humiliating disclosures, while grading work that discloses suffering raises concern that any criticism could exacerbate a student's problems. Two strategies tend to discourage personal revelations and 'unleashing of affect' in the writing classroom according to Bishop: an emphasis on craft, rather than on 'discovery through writing', and a requirement that students focus 'exclusively on the text, never on the author' (1993: 504). Such strategies, however, can prove counterproductive. Carolyn Jess-Cooke recalls that her creative writing classes triggered painful memories, but 'not once' did the class explore 'those elements of writing creatively that involve painful memories, the powerful role of the subconscious in creative writing', as the focus was purely on craft and technical matters. Consequently, it has taken her many years 'to understand how to negotiate the wellspring of personal narratives' (2015: 250) her writing draws on. Now teaching, she proposes that creative writing classes integrate 'resilience strategies in terms of cognitive development, bringing writers to a fuller awareness of process' (2015: 255).

Tara DaPra's 'Introduction to Creative Nonfiction' class received a warning from the instructor on the first day: 'This class is not therapy' (2013). This issue worried DaPra because she had found writing 'very therapeutic' in the wake of her boyfriend's suicide. The instructor later agreed it was, but her aim had been to discourage students from submitting 'diary entries about what jerks their boyfriends were'. DaPra notes that 'academia - like the larger culture - remains anxious about crossing into the land of therapy': she recommends a less prejudicial approach that encourages reflection and revision, and the Writing Therapy unit aims to provide just such a space and to speak explicitly about these various approaches and concerns so that students can make informed decisions about their writing. Even so, the unit plan for Writing Therapy cautions that 'therapy is not one of the unit's stated aims, objectives, or outcomes and 
nor is the notion of writing as a form of therapy incontestable.' It also states that the unit is not run by a trained therapist or counsellor, does not conduct writing workshops in the way of a qualified arts therapist and 'cannot provide professional medical or therapeutic advice or assistance.' Students seeking or receiving therapy in any context are advised to discuss the unit content with their doctor or therapist. This is to point out limitations rather than suppress affects, which are integral to transformative learning (Walker and Palacios 2016: 187).

Given that writing can cause distress or raise anxiety at times, even if usually shortterm, workshop safeguards need to be put in place. We discuss at some length issues of empathy, care, respect and confidentiality because the role of the reader or listener is crucial: an empathetic response may reduce the possibility of 'contagion' or (re)traumatisation. It is particularly important that students understand the risks and how to seek assistance should negative feelings prove overwhelming or persistent. There is a difference, though, between saying a creative writing class is not therapy (most will not assume it to be) and saying that Writing Therapy is not therapy. In both instances, there is a chance there will be therapeutic elements for some students but, as noted, writing might also stir up trouble. And if the writing is self-disclosing or contentious and then gets published, the trouble may worsen because readers may not be appreciative and forgiving and writers risk being shamed by their disclosures. This view contrasts with what many students imagine - that publication will win them only affection and success. Amid contemporary enthusiasm for writing as an accessible, cost-efficient therapeutic practice that can be undertaken with or without medical oversight, we need to remember the unpredictable aspects of creativity: writing can be 'a risky business' (Hecq 2015: 4) and stories are 'sometimes generative, sometimes stultifying or even destructive' (Clark 2008: 4).

It is possible for university writing classes to effect shaming or silencing because writing does not always produce the expected or desired interpretation and response. In a typical controlled expressive writing trial, the response risk is diminished because participants receive no feedback and are assured their narratives will be de-identified. In a clinical or community setting where writing is facilitated by qualified arts therapists, feedback is circumscribed and supportive; empathic practices are paramount. When marking 'risky writing', Berman gives pass or fail grades and restricts feedback to technical matters. In my Writing Therapy unit, students sometimes take up an opportunity to discuss or read aloud the results of a writing experiment, but there is no pressure to share. The criteria for written assignments require them to consider the reader, ethical issues, and possible problems of disclosure, which means that as drafting progresses they may experience less freedom than in journaling and free-writing exercises.

\section{Writing a better future?}

Stephen Clift, co-editor of the Oxford textbook of creative arts, health and wellbeing (2016), observed in 2012 the 'emergence of a new "wellness" agenda globally' that questions the relation of aesthetics to the field of health and refers to 'the positive resources people have both personally and in their social and physical environments ... 
to promote a sense of wellbeing (120-21). The UK's National Alliance for Arts, Health and Wellbeing was launched that same year 'to provide a clear, focused voice to articulate the role creativity can play in health and wellbeing'. It states in its charter that the 'arts, creativity and the imagination are agents of wellness: they help keep the individual resilient, aid recovery and foster a flourishing society' (National Alliance 2012: 1). The previous year in the US, the National Endowment for the Arts had, in partnership with the US Department of Health and Human Services, released a national research agenda for the 'arts, lifelong learning, and individual wellbeing', claiming that in 'study after study, arts participation and arts education have been associated with improved cognitive, social, and behavioral outcomes in individuals across the lifespan' (National Endowment 2011: 7).

In 2013, Australia's National Arts and Health Framework was endorsed, with the aim of 'improving the health and wellbeing of all Australians' (National Arts 2013: 1). It recognises arts and health as 'a specific and often specialised genre of arts practice' that has 'its own intrinsic value' but also a 'focus on achieving health and wellbeing outcomes and reducing health inequality'. The framework includes 'all art forms and artistic media', such as 'visual arts, craft and design, writing, literature and storytelling, music, performing arts, dance, theatre, film and digital arts' (6). It indicates 'arts and health' can be many things, including a 'therapy, rehabilitation or treatment in itself'; a 'tool' to promote 'healthy living'; a 'means of inclusion and link between members of socially isolated groups'; a way of improving 'empathy and communication skills amongst health professionals'; and a means of 'individual self-expression and personal development' (24).

Notably, though, literary practices receive less attention than other arts in these and other sites that link arts, health and wellbeing, with music, performing and visual arts much more evident. This is despite the fact that therapeutic writing has been progressed and legitimated internationally over the past thirty years by the establishment of dedicated peer review journals, professional associations and credentialing processes, and the use of creative writing in health and social care (Sampson 2004). Furthermore, writing has a low profile in key Australian arts therapy associations: to my knowledge, there are no dedicated therapeutic writing organisations to compare, for example, with Lapidus: The Writing for Wellbeing Organisation in the UK and the National Association for Poetry Therapy in the US. Furthermore, only a few Australian universities offer arts therapy courses: these focus mostly on the visual and performing arts.

Powell describes writing as 'the most important technology in the history of the human species, except how to make a fire', for it is 'the lens through which literate peoples see the world, feel the world, hate the world, love the world, defy the world, and imagine change' (2009: 11). Despite rising confidence in writing as also potentially remedial, its linguistic, representational and symbolic complexities, as well as its potency, may work against its pervasive use. Interestingly, Clift argues that with arts interventions 'we are not dealing with ... forms of invasive treatments where there are risks to be weighed against possible benefits' (2012: 124). But writing, I am suggesting, can be invasive and it seems we do need to weigh up risks against possible benefits; we can attempt to handle it knowingly. 
Clift recognises a 'hierarchy of evidence' in the field of health care that favours quantitative studies using random control trials but, as he points out, 'there are many research questions these cannot answer', including how an intervention works and whether it is appropriate for and acceptable to potential participants. Beneficial qualitative methods of data collection and evaluation can be used, Clift asserts, including observation, interviews, focus group discussions and case studies, together with 'analytical techniques such as narrative, thematic and content analysis' to allow 'deeper evaluation' (123). Stuckey and Nobel point out in their review of art and health literature that traditionally 'scientists involved with statistics have not partnered with those in the arts community': they propose that in future teams 'should be created to form an effective triad of experts' comprising 'solid research methodology experts (i.e., biostatisticians), clinical experts, and those with artistic expertise in the community' (2010: 261).

The time seems ripe in Australia for writing and health educators and researchers to investigate writing's risks and recuperative possibilities collaboratively. Writing researchers could productively join forces with qualitative and quantitative researchers from diverse fields including but not limited to psychology, medicine and the social sciences. Broadly, research could test the efficacy of engaging various student cohorts in expressive and literary writing, with a view to introducing well-designed interventions that contribute to health and wellbeing strategies deployed by universities.

On the local level, I expect future collaborative research involving informed and consenting student participants usefully to influence writing pedagogy. To date, expressive writing studies have been conducted with numerous and diverse populations, including, in many instances, healthy college students, but none to my knowledge has targeted university students who have studied therapeutic writing. Such a cohort may seem unpromising for what Stuckey and Nobel would caution against proliferating, that is, studies that use "convenience samples", for these can introduce a number of potential confounding factors such as responder bias as well as limiting the generalizability of the findings to other populations' (2010: 261). However, not only do convenience samples make sense in some cases but also reflective methods can interrogate bias in revelatory ways. Furthermore, while much research to date tests whether writing produces beneficial physiological, cognitive or emotional changes or reduces anxiety and other debilitating conditions, it does not consider the potential benefits of informed practice in this field.

\section{Endnotes}

1. The Bachelor of Arts degree comprises 24 units of study, with each taking one semester to complete. The Writing Therapy unit is also available as part of a Psychology and Writing double major in the Bachelor of Arts (Psychology).

2. Epston and White's influential work Narrative means to therapeutic ends (1990) was originally published as 'Literary means to therapeutic ends' in 1989.

3. The method for unit creation involves cycles of planning, designing, drafting, editing, executing, reflecting, reviewing and revising, drawing for each iteration on further investigations of the (growing) literature in the field, observation, and student views in essays, 
conversations, class discussions, emails and Unit and Teaching Evaluation Instruments (UTEIs), though to date these sources have not been systematically analysed.

4. For example, students read 'What is narrative therapy?' (Morgan 2000), discover journals of literature and medicine and the Literature, Arts and Medicine Database (LitMed), review the tenets and uses of medical humanities (Charon 2006; Cowen, Kaufman and Schoenherr 2016) and consider ethical questions and guidelines, such as 'A critique of current practice: Ten foundational guidelines for autoethnographers' (Tolich 2010). In addition, they review websites of organisations with politico-therapeutic aims.

5. Sources include overviews of quantitative research in the field such as The Writing Cure: How expressive writing promotes health and emotional wellbeing (Lepore and Smyth 2002); explanatory texts for writers, educators and writing therapists, such Writing works: A resource handbook for therapeutic writing workshops and activities (Bolton, Field and Thompson 2006) and works focused on specific applications, with theoretical and ethical considerations, such as Creative writing in health and social care (Sampson 2004) and Behind the lines: Creative writing with offenders and people at risk (Cowley 2012).

6. Winnicott's theory of transitional space is useful as a way to conceptualise the space of writing as a playground for the imagination, that is, as a place partaking of and in-between fantasy and reality (Robinson 2000; Baker 2009).

7. See Jolly (2011) for an explanation of letter therapy and its various applications.

8. Other relevant works by Berman include Diaries to an English professor: Pain and growth in the classroom (1994) and Cutting and the pedagogy of self-disclosure (2008).

\section{Works cited}

Adams, K 2006 'What people need to write', in G Bolton, V Field and K Thompson (eds) Writing works: A resource handbook for therapeutic writing workshops and activities, Jessica Kingsley, London

Arts and Letters 2007 'Creative writing and the Virginia Tech massacre' U of Notre Dame https://al.nd.edu/news/12735-creative-writing-and-the-virginia-tech-massacre (accessed 8 May 2016)

Baikie, KA and K Wilhelm 2005 'Emotional and physical health benefits of expressive writing', Advances in psychiatric treatment 11, 5: 338-46

Baker, S 2009 'Tell it slant: History, memory, and imagination in the healing writing workshop', Traumatology 15, 4: 15-23

Benesch, S 2008 [2001] Critical English for academic purposes: Theory, politics, and practice, Taylor \& Francis e-Library

Berman, J 2001 'Risky writing': Self-disclosure and self-transformation in the classroom, U of Massachusetts P, Amherst

Bishop, W 1993 'Writing is/and therapy?: Raising questions about writing classrooms and writing program administration', Journal of advanced composition 13, 2: 503-16

Bolton, G, V Field and K Thompson 2011 Writing routes: A resource handbook of therapeutic writing, Jessica Kingsley, London

Brooks, P 1992 Reading for the plot: Design and intention in narrative, Harvard UP, Cambridge, MA

Bucci, W 1995 'The power of the narrative: a multiple code account' in J W Pennebaker (ed) Emotion, disclosure and health, American Psychological Association, Washington

Charon, R 2006 Narrative Medicine: Honoring the stories of illness, Oxford UP, New York

Chavis, GG 2011 Poetry and story therapy: The healing power of creative expression, Jessica Kingsley, London

Clark, H (ed) 2008 Depression and narrative: Telling the dark, State U of New York P, Albany 
Clift, S 2012 'Creative arts as a public health resource: moving from practice-based research to evidence-based practice', Perspectives in public health 132, 3: 120-7

Clift, S and P Camic 2016 (eds) Oxford textbook of creative arts, health and wellbeing, Oxford UP, Oxford

Cowan, S, D Kaufman and L Schoenherr 2016 'A review of creative and expressive writing as a pedagogical tool in medical information', Medical education 50: 311-9

Croom, AM 2015 'The practice of poetry and the psychology of well-being', Journal of poetry therapy 28, 1: 21-41

Crowley, M 2012 Behind the lines: Creative writing with offenders and people at risk, Waterside $\mathrm{P}$, Hampshire

DaPra, T 2013 'Writing memoir and writing for therapy: An inquiry on the function of reflection' Creative nonfiction, 48: https://www.creativenonfiction.org/online-reading/writing-memoir-andwriting-therapy (accessed 8 May 2016)

DeSalvo, L 1999 Writing as a way of healing: How telling stories transforms our lives, Beacon P, Boston

Dutro, E 2011 'Writing wounded: Trauma, testimony, and critical witness in literacy classrooms', English education 43: 2, 193-210

Ecclestone, K and D Hayes 2009 The dangerous rise of therapeutic education, Routledge, London

Embedding Research Informed Teaching 2013 Centre for Learning and Development, Edith Cowan U http://intranet.ecu.edu.au/_data/assets/pdf_file/0007/655774/Embedding-research-informed-teachinghow-to-do-it-guide.pdf (accessed 15 November 2016)

Epston D and M White 1990 Narrative means to therapeutic ends, Norton, New York

Felman, S 1995 'Education and crisis, or the vicissitudes of teaching' in (ed) C Caruth Trauma: Explorations in memory, Johns Hopkins UP, Baltimore

Forgeard, MJC, SB Kaufman and JC Kaufman 2013 The psychology of creative writing in G Harper (ed) A companion to creative writing, Wiley-Blackwell, Chichester, West Sussex

Foster, D 1987 Confession and complicity in narrative, Cambridge UP, Cambridge

Foucault, M 1988 'Technologies of the self: A seminar' in (eds) LH Martin, H Gutman \& PH Hutton Technologies of the self: A seminar with Michel Foucault, U of Massachusetts P, Amherst

Frank, A 1995 The wounded storyteller, U of Chicago P, London

Friedman, S 2007 'Changing the subject: First-person narration in and out of the classroom' Dissertation, U of South Florida, UMI Number: 3298352

Furedi, F 2004 Therapy culture: Cultivating vulnerability in an uncertain age, Routledge, London

Gortner, E, SS Rude and JW Pennebaker 2006 'Benefits of expressive writing in lowering rumination and depressive symptoms', Behavior therapy 37: 292-303

Hecq, D 2015 Towards a poetics of creative writing, Multilingual matters, Bristol

Hunt, C 2000 Therapeutic dimensions of autobiography in creative writing, Jessica Kingsley, London

Jess-Cooke, C 2015 'Should creative writing courses teach ways of building resilience?' New writing: The international journal for the practice and theory of creative writing, 12,2: 249-59

Jolly, M 2011 'What I never wanted to tell you: Therapeutic letter writing in cultural context', Journal of Medical Humanities, 32: 47-59

Kaufman, SB and ES Paul 2014 'Creativity and schizophrenia spectrum disorders across the arts and sciences’ Frontiers in psychology 5:1145

Keating, DM and SA Rains 2014 'Expressive writing and health' in TL Thompson (ed) Encyclopedia of health communication, Sage, Los Angeles 
King, R, F Baker and P Neilsen 2016 Creative arts in counselling and mental health, Sage, Thousand Oaks

Larcombe, W, S Finch, R Sore, CM Murray, S Kentish, RA Mulder, P Lee-Stecum, C Baik, O Tokatlidis and DA Williams 2014 'Prevalence and socio-demographic correlates of psychological distress among students at an Australian university' Studies in higher education, DOI: 10.1080/03075079.2014.966072

Lepore, SJ and JM Smyth 2002 The writing cure: How expressive writing promotes health and emotional well-being American Psychological Association

Lu, Q and AL Stanton 2010 'How benefits of expressive writing vary as a function of writing instructions, ethnicity and ambivalence over emotional expression', Psychology \& health, 25, 6: 669684

Morgan, A 2000 'What is narrative therapy?’ Dulwich Centre: http://dulwichcentre.com.au/what-isnarrative-therapy (accessed 8 May 2016)

Morrison, B 2007 'Can a killer's literary efforts tell us anything about his motives?' The Guardian 19 April: http://www.guardian.co.uk/education/2007/apr/19/internationaleducationnews.highereducation (accessed 31 July 2008)

Murphy, F 2006 Devotion, Fremantle P, Perth

Murphy, F 2008 'Shots in the dark: Writing, revelation, and responsibility, Creativity and Uncertainty', Proceedings of the Australasian Association of Writing Programs:

http://d3n8a8pro7vhmx.cloudfront.net/theaawp/pages/83/attachments/original/1385079374/Murphy_06 09.pdf?1385079374 (accessed 8 May 2016)

National Alliance for Arts, Health and Wellbeing 2012 'Charter for arts, health and wellbeing' http://www.artshealthandwellbeing.org.uk/what-is-arts-in-health/charter-arts-health-wellbeing (accessed 28 November 2016)

National Arts and Health Framework 2013 Department of Communication and the Arts, Australian Government https://www.arts.gov.au/sites/g/files/net1761/f/National\%20Arts\%20and\%20Health\%20Framework\%2 0May\%202014.pdf (accessed 28 November 2016)

National Endowment for the Arts 2011 The arts and human development: Framing a national research agenda for the arts, lifelong learning, and individual well-being, NEA Office of Research and Analysis https://www.arts.gov/sites/default/files/TheArtsAndHumanDev.pdf (accessed 20 April 2016)

Norton, J and M Brett 2011 'Seeking help for struggling students', HES, The Australian, 13 July http://www.theaustralian.com.au/higher-education/seeking-help-for-struggling-students/story-e6frgcjx1226093346837 (accessed 15 November 2016)

Pennebaker, JW 2010 'Expressive writing in a clinical setting' The independent practitioner 30: 23-25: http://homepage.psy.utexas.edu/HomePage/Faculty/Pennebaker/Reprints/Pennebaker_IP2010.pdf (accessed 8 May 2016)

Pennebaker, JW and SK Beall 1986 'Confronting a traumatic event: Toward an understanding of inhibition and disease' Journal of Abnormal Psychology, 95: 274-81

Pennebaker, JW and CK Chung 2007 'Expressive writing, emotional upheavals, and health' in H S Friedman and R Cohen Silver (eds) Foundations of health psychology, Oxford UP, Oxford

Petro, M 2013 'The writing cure', The new inquiry 7 Nov: http://thenewinquiry.com/essays/thewriting-cure (accessed 29 April 2016)

Powell, B. 2009 Writing: Theory and history of the technology of civilization, Wiley-Blackwell, Malden, MA

Rainer, T 2004 [1978] The new diary, Tarcher/Penguin, New York

Range, LM and SR Jenkins 2010 'Who benefits from Pennebaker's expressive writing paradigm? Research recommendations from three gender theories', Sex roles 63, 3: 149-64 
Robinson, M 2000 'Writing well: health and the power to make images', Journal of medical ethics 26, 6: $79-84$

Sampson, F 2004 Creative writing in health and social care, Jessica Kingsley, London

Sexton, JD and JW Pennebaker 2009 'The Healing Powers of Expressive Writing' in S B Kaufman and JC Kaufman (eds) The psychology of creative writing, Cambridge UP, New York: 265-73

Schlesinger, J 2009 'Creative Mythconceptions: A closer look at the evidence for the "mad genius" hypothesis' Psychology of aesthetics, creativity, and the arts 3, 2: 62-72

Spear, NR 2014 “"Let me tell you a story”: On teaching trauma narratives, writing, and healing' Pedagogy 14, 1: 53-79

Stallman, HM 2010 'Psychological distress in university students: A comparison with general population data' Australian psychologist 45, 4: 249-57

Stuckey, HL and J Nobel 2010 'The connection between art, healing, and public health: A review of current literature’ American Journal of Public Health, 100, 2: 254-63

Thompson, K 2006 'What people need to write' in G Bolton, V Field and K Thompson (eds) Writing works: A resource handbook for therapeutic writing workshops and activities, Jessica Kingsley, London

Tolich, M 2010 'A critique of current practice: Ten foundational guidelines for autoethnographers', Qualitative health research 20, 12: 1599-1610

Travagin, G, D Margola and TA Revenson 2015 'How effective are expressive writing interventions for adolescents? A meta-analytic review’, Clinical psychology review 36: 42-55

Walker, J and C Palacios 2016 'A pedagogy of emotion in teaching about social movement learning', Teaching in higher education, 21, 2: 175-90

Wynaden, D, H Wichmann and S Murray 2013 'A synopsis of the mental health concerns of university students: Results of a text-based online survey from one Australian university', Higher education and development, 32, 5: 846-60 